\title{
High-performance liquid chromatographic determination of 2-furaldehyde and 5-hydroxymethyl-2-furaldehyde in honey
}

\author{
Filippo Lo Coco ${ }^{\mathrm{a}}$, Clemente Valentini ${ }^{\mathrm{b}}$, Veronica Novelli ${ }^{\mathrm{a}}$, Luciano Ceccon ${ }^{\mathrm{c} \cdot *}$ \\ a Dipartimento di Scienze e Tecnologie Chimiche, Università di Udine, Via Cotonificio 108, 33100 Udine. Italy \\ 'Laboratorio Chimico delle Dogane di Venezia, Via Ca' Marcello 15, 30172 Mestre. Italy \\ "Dipartimento di Economia e Merceologia delle Risorse Naturali e della Produzione, Università di Trieste. Via Valerio 6. \\ 34127 Trieste, Italy
}

Received 14 November 1995; revised 19 April 1996; accepted 19 April 1996

\begin{abstract}
A method of determination of 2-furaldehyde (F) and 5-hydroxymethyl-2-furaldehyde (HMF) in honey by highperformance liquid chromatography (HPLC) is described. The method is based on the formation of the 2,4-dinitrophenylhydrazones of carbonyl compounds and subsequent reversed-phase separation of these derivatives. Derivatization is carried out by utilizing an acidic solution of 2,4-dinitrophenylhydrazine in acetonitrile. Precipitation of the derivatives of carbonyl compounds is thus avoided and direct injection of the sample into the HPLC system is allowed. The procedure offers a high specificity, since the derivatives of $\mathrm{F}$ and $\mathrm{HMF}$ are well separated from the other components of the mixture under examination. Recoveries of 95-99\% were obtained from honey spiked at different levels with both analytes. The detection limit is of the order of $10 \mu \mathrm{g} / \mathrm{kg}$ of honey and reproducibility (mean of six determinations) is $\pm 3 \%$ for $\mathrm{F}$ and $\pm 2 \%$ for HMF.
\end{abstract}

Keywords: Honey; Food analysis; Furaldehyde; Hydroxymethylfuraldehyde; Aldehydes

\section{Introduction}

The preservation of honey quality during processing and storage is of primary importance to safeguard the health giving properties of this product. For many years deterioration of flavour, enzyme content and color, and increased 5-hydroxymethyl-2furaldehyde (HMF) production have been assumed as indications of quality losses [1-6]. In particular the amount of HMF, which is produced by action of

\footnotetext{
${ }^{*}$ Corresponding author.
}

the normal honey acidity on fructose at room temperature, increases notably owing to thermic treatments and/or storage at improper temperatures [110]. HMF is correlated with browning reactions that occur not only in honey, but in several food products $[5,9,11-13]$. The regulations of several countries and the Codex Alimentarius Commission Standards fix a minimum amount of 8 units of diastatic activity and an upper limit of $40 \mathrm{mg} \mathrm{HMF} / \mathrm{kg}$ of honey to assure that honey has not been denatured by heat $[3,4,6,7,9,14]$. Extremely high $(>500 \mathrm{mg} / \mathrm{kg}$ ) HMF values demonstrate an adulteration with invert syrup 
$[3,8]$. On the other hand, a close relationship between flavour changes and 2-furaldehyde (F) content has been demonstrated in several food matrices; for this reason, the $\mathrm{F}$ content is useful as an off-flavour indicator $[11,13,15,16]$.

The classical methods for the qualitative identification of carbonyl compounds were based on colorimetric procedures $[17,18]$ and were later adapted for quantitative purposes [19]. Afterwards, spectrophotometric procedures were also developed [20]. However, both the colorimetric and spectrophotometric methods (i) are time consuming, (ii) make use of toxic or anyhow hazardous chemicals, (iii) require a strict control of both reaction time and temperature, since the instability of the reaction product may lead to low recoveries and wide statistical variations of the results and (iv) none of the methods is specific [3-5,7-10,12,21-23]. Consequently, several chromatographic methods were developed that allow the determination of the individual carbonyls by paper chromatography $[24,25]$, classical liquid-liquid partition chromatography [26], thin-layer chromatography [27], gas chromatography [28-30] or high-pressure liquid chromatography (HPLC) [22,31]. These methods are less time consuming, offer improved accuracy, sensitivity and specificity as compared to the colorimetric and spectrophotometric procedures and utilize less hazardous reagents $[4,9,10,21]$.

However, the preparation of a derivative of the carbonyl compounds is often needed in order to enhance both the selectivity and sensitivity of the method. This allows the quantitation of trace amounts of carbonyls in several matrices [22,23,31]. The most widely utilized derivative is the corresponding 2,4-dinitrophenylhydrazone (DNPH-one); in fact, (i) the reaction between 2,4-dinitrophenylhydrazine (DNPH) and carbonyl compounds is highly specific and (ii) the use of DNPH as the reagent provides a rather rapid sample preparation, thus minimizing background effects [32].

In this paper, a method is described for the determination of $\mathrm{F}$ and HMF in honey that is based on the formation of the DNPH-ones of carbonyl compounds. The DNPH-ones obtained are then separated by HPLC and determined with spectrophotometric detection.

\section{Materials and methods}

\subsection{Standards and reagents}

F (Prolabo, Paris, France) was doubly distilled at atmospheric pressure; the fraction with a boiling point of $161-163^{\circ} \mathrm{C}$ was collected and kept in an airtight vial at $-20^{\circ} \mathrm{C}$ to prevent browning of the product.

Both HMF and DNPH (Prolabo) were purified by successive crystallizations with HPLC grade methanol and kept in a refrigerator at $0-4^{\circ} \mathrm{C}$.

The Carrez clarification reagent (Carlo Erba, Milan, Italy) consisted of a $15 \%(w / v)$ solution of Carrez I (potassium ferrocyanide) and of a $30 \%$ (w/v) solution of Carrez II (zinc sulfate).

Perchloric acid (70\%) was obtained from Prolabo and acetonitrile (HPLC grade) from Carlo Erba. Water was distilled, deionized and then further purified with a Milli-Q system (Millipore, Milford, MA, USA).

\subsection{2,4-Dinitrophenylhydrazine solutions}

A stock reagent solution containing $2.5 \cdot 10^{-3} \mathrm{~mol} /$ 1 of DNPH was prepared in acetonitrile. By successive dilutions, reagent solutions containing down to $2.5 \cdot 10^{-6} \mathrm{~mol} / 1$ of DNPH were prepared.

\subsection{2-Furaldehyde and 5-hydroxymethyl-2- furaldehyde standard solutions}

A stock standard solution containing $1.0 \cdot 10^{-2}$ $\mathrm{mol} / \mathrm{l}$ of both $\mathrm{F}$ and HMF was prepared in water. By successive dilutions, working standard solutions containing down to $1.0 \cdot 10^{-7} \mathrm{~mol} / 1$ of both analytes were prepared.

Two aqueous solutions containing $10^{-4} \mathrm{~mol} / 1$ of $\mathrm{F}$ and HMF were also prepared.

\subsection{Calibration graphs}

A 5-ml volume of each working standard solution and 4-ml of a 5 times more concentrated DNPH solution were transferred into a $10-\mathrm{ml}$ glass-stoppered volumetric flask. A $0.4-\mathrm{ml}$ volume of perchloric acid was added and the volume was made up 
to the mark with the DNPH solution. The content of the volumetric flask was transferred into a $25-\mathrm{ml}$ beaker and the $\mathrm{pH}$ was eventually adjusted to 1 . The beaker was kept on a magnetic stirrer at room temperature for at least $25 \mathrm{~min}$, then $10 \mu \mathrm{l}$ of the solution were immediately injected into the HPLC system.

\subsection{Sample processing}

Honey was homogenized by stirring with a spatula and a $40 \%(\mathrm{w} / \mathrm{v})$ aqueous solution was prepared. A $10-\mathrm{ml}$ volume of the aqueous solution was pipetted into a $50-\mathrm{ml}$ beaker, $2-\mathrm{ml}$ of Carrez $\mathrm{I}$ and $2-\mathrm{ml}$ of Carrez II solution were added slowly with gentle mixing to allow the turbidity of the sample to be eliminated. After standing for $5 \mathrm{~min}$, the mixture was filtered through a Milli-Q system, under suction, into a $25-\mathrm{ml}$ volumetric flask, the filter was washed with distilled water, washings were added to the filtrate and the volume taken up to the mark with distilled water. The same procedure as described under Section 2.4 was applied to a $5-\mathrm{ml}$ volume of the clarified honey solution instead of working standard solution. The acetonitrile solution of the DNPH-ones of carbonyl compounds was centrifuged for $3 \mathrm{~min}$ at $150 \mathrm{~g}$ before injection into the HPLC system. A syringe attached to a Millex-LCR ${ }_{13}$ (Millipore) was used to remove all particles larger than $0.5 \mu \mathrm{m}$.

\subsection{Determination of recoveries}

To 10-ml of aqueous honey solution was added a $2.5-\mathrm{ml}$ volume of a working standard solution containing from $1.0 \cdot 10^{-2}$ down to $1.0 \cdot 10^{-6} \mathrm{~mol} / \mathrm{l}$ of both $\mathrm{F}$ and HMF. The sample obtained was subjected to the procedure described under Section 2.5. Each determination was carried out in triplicate: each solution was injected twice.

\subsection{High-performance liquid chromatography}

A Spectra-Physics Model 8700 (Carlo Erba) highperformance liquid chromatograph, equipped with a Knauer Model 8700 variable-wavelength spectrophotometric detector (Knauer, Berlin, Germany) and a $10-\mu l$ loop, was used. A Supelcosil LC-18
(Supelco, Bellefonte, PA, USA) stainless-steel column $(250 \times 4.6 \mathrm{~mm}$ I.D.; film thickness $5 \mu \mathrm{m})$ was employed. Analyses were carried out isocratically at room temperature with acetonitrile-water $(55: 45, \mathrm{v} /$ v) as the eluent at a flow-rate of $1-\mathrm{ml} / \mathrm{min}$. The spectrophotometric detector was set at $385 \mathrm{~nm}$.

Peak areas were determined by means of a Spectra-Physics Model 4270 integrator.

\subsection{High-performance liquid chromatography- mass spectrometry}

The same HPLC system described in the preceding section was employed, with the exception that a preparative column $(250 \times 10 \mathrm{~mm} \mathrm{I.D.})$ and a $50-\mu \mathrm{l}$ loop were used. A $400 \%(\mathrm{w} / \mathrm{v})$ aqueous honey solution was processed. The water-acetonitrile solution of the DNPH-ones of carbonyl compounds was reduced to a $2-\mathrm{ml}$ volume in a rotary vacuum evaporator at $60^{\circ} \mathrm{C}$; ten $50-\mu \mathrm{l}$ aliquots were successively injected into the HPLC system. The fractions corresponding to the elution of the two analytes of interest were collected in two different vials and dried in a stream of nitrogen. The two solid samples obtained (about $100 \mu \mathrm{g}$ each) were directly introduced into the mass spectrometric system. A Hewlett-Packard Model 5988A (Hewlett-Packard, Palo Alto, CA, USA) mass spectrometer, equipped with a direct insertion probe source, was used; fragmentation was induced under a $70 \mathrm{eV}$ electron impact.

\subsection{Statistical analysis}

A Student's $t$-test was used to determine if significant differences existed among results obtained under different experimental conditions.

\section{Results and discussion}

\subsection{Optimization of the derivatization step}

In recent years HPLC has been employed for the determination of $\mathrm{F}$ and/or HMF in honey $[4,6,9,10,12,21]$. The advantages of the HPLC procedures in respect of the classical methods have been highlighted by several authors $[4,9,10,12,21]$. The 
HPLC methods so far proposed provide for the injection of the sample without derivatization. However, we made the honey solution undergo derivatization in order to obtain the DNPH-ones of the carbonyl compounds present. The sensitivity and selectivity of the method can therefore be improved.

The DNPH-ones are usually obtained by employing an excess of DNPH aqueous solution in the presence of hydrochloric acid. The utilization of an acetonitrile DNPH solution in the presence of perchloric acid offers the advantage of obtaining a solution of the derivatives that may be injected directly into the HPLC system [23,32]. Long and tedious steps, such as filtration and washing of the derivatives obtained in aqueous solution and preparation of a derivative solution in a suitable solvent before the HPLC determination, may therefore be avoided [23,32]. The use of perchloric acid instead of hydrochloric acid is due to its higher solubility in acetonitrile [23].

The derivatization step was optimized by us with respect to three parameters: (1) the DNPH-to-analyte molar ratio, (2) the acidity of the medium and (3) the reaction time. For this purpose, the amounts of the derivatives obtained were evaluated on two aqueous standard solutions containing respectively $F$ and HMF, both $10^{-4} \mathrm{~mol} / \mathrm{l}$. The results obtained are shown in Fig. 1, Fig. 2 and Fig. 3. As may be seen, the derivatization reaction is quantitative when the reagent-to-analyte ratio is at least 2.5:1 for both analytes and the acidity of the medium, as evaluated with a pH meter, is about 1 . Under these conditions, both $\mathrm{F}$ and HMF are quantitatively converted into their DNPH-ones within $25 \mathrm{~min}$. The derivatives obtained are stable at room temperature for at least $48 \mathrm{~h}$.

\subsection{Calibration}

The calibration graphs were obtained by employing standard solutions of both $F$ and HMF under optimum experimental conditions as described in the preceding section. A straight line was obtained for both analytes over the range of concentrations from

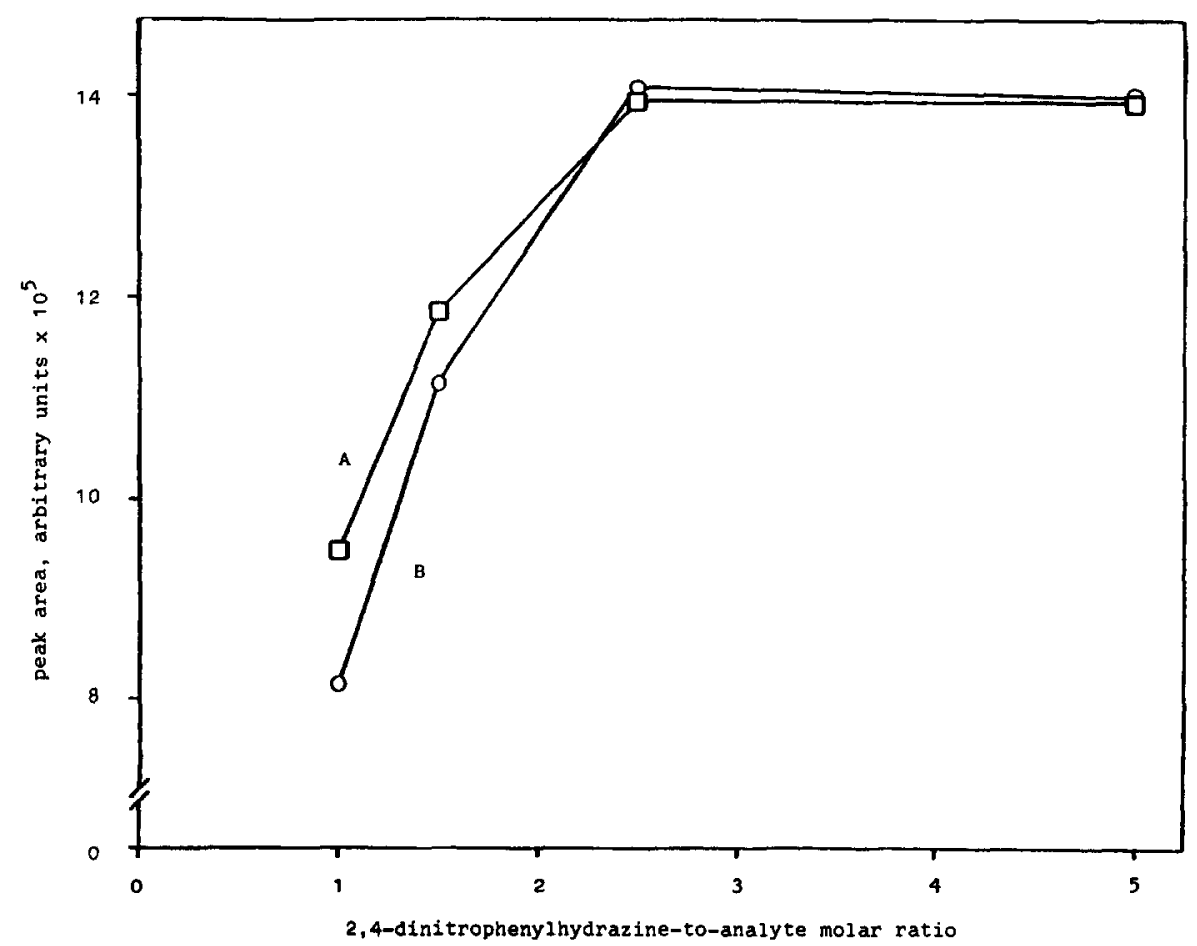

Fig. 1. Conversion of 2-furaldehyde (A) and 5-hydroxymethyl-2-furaldehyde (B) to their 2,4-dinitrophenylhydrazones as a function of the 2,4-dinitrophenylhydrazine-to-analyte molar ratio. $\mathrm{pH}$ of the medium $=1$, reaction time $=30 \mathrm{~min}$. 


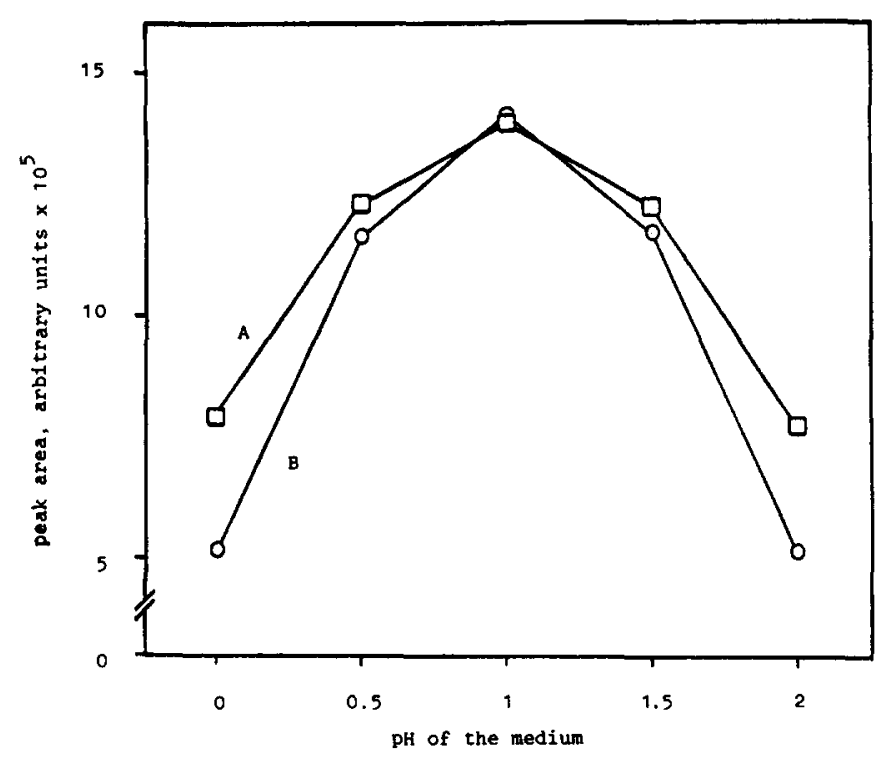

Fig. 2. Conversion of 2-furaldehyde (A) and 5-hydroxymethyl-2-furaldehyde (B) to their 2,4-dinitrophenylhydrazones as a function of the acidity of the medium. 2,4-Dinitrophenylhydrazine-to-analyte molar ratio $=2.5$, reaction time $=30 \mathrm{~min}$.

$10^{-3}$ to $10^{-7} \mathrm{~mol} / \mathrm{l}$, which represent values typically found in real samples. The parameters of the linear regression relative to the bilogarithmic plot of the
DNPH-one area versus the concentration of the analyte of interest in the sample under examination were: for F, slope 1.0014 , intercept 10.1501 , stan-

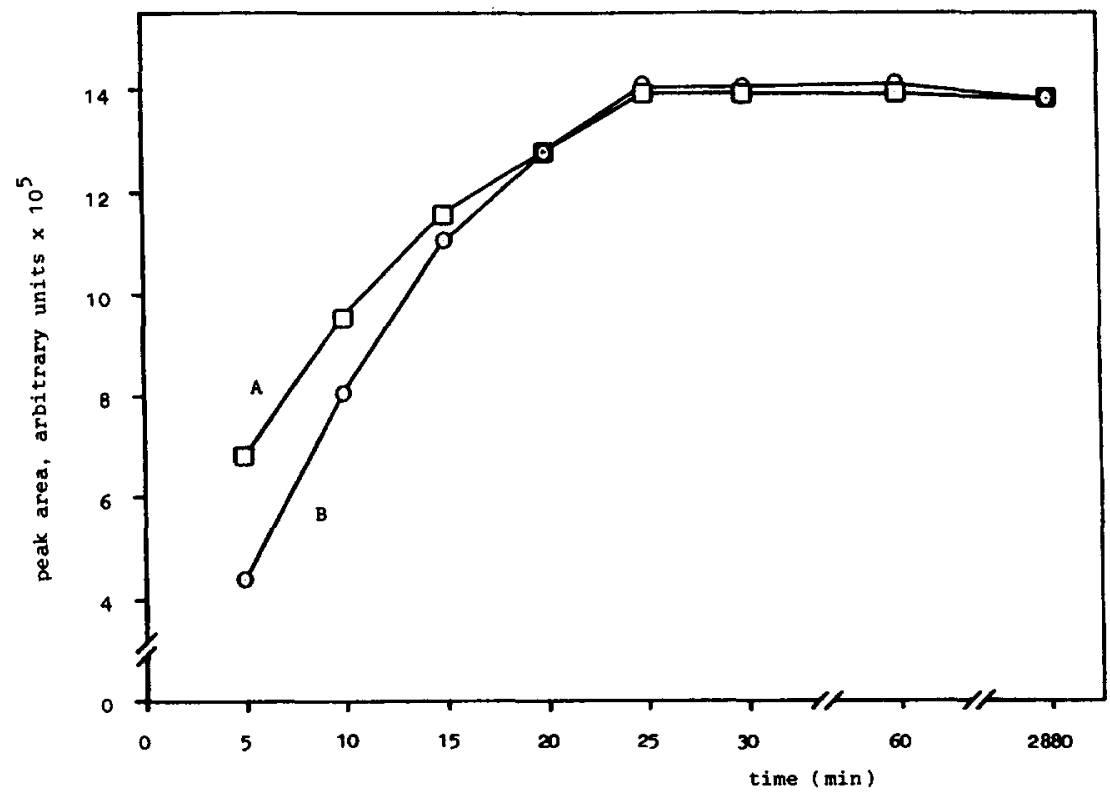

Fig. 3. Conversion of 2-furaldehyde (A) and 5-hydroxymethyl-2-furaldehyde (B) to their 2,4-dinitrophenylhydrazones as a function of reaction time. 2,4-Dinitrophenylhydrazine-to-analyte molar ratio $=2.5, \mathrm{pH}$ of the medium $=1$. 
dard deviation of the slope 0.0010 , standard deviation of the intercept 0.0053 , standard error 0.0080 , number of data points $=6$ (six replicates of each point), correlation coefficient 0.999985; for HMF, slope 1.0098 , intercept 10.1781 , standard deviation of the slope 0.0015 , standard deviation of the intercept 0.0076 , standard error 0.0113 , number of data points $=6$ (six replicates of each point), correlation coefficient 0.999971 .

By setting the detector wavelength at the maximum absorbance of the derivatives of both $F$ and HMF, it is possible to determine the detection limit as $3 \sigma / \mathrm{S}$ [33], where $\mathrm{S}$ is the sensitivity, which is $1.39 \cdot 10^{10}$ for $\mathrm{F}$ and $1.26 \cdot 10^{10}$ for HMF as obtained from the calibration graphs, and $\sigma$ is the peak threshold of the integrator, which was set by us at 100. The detection limits are therefore $2.2 \cdot 10^{-8} \mathrm{~mol} /$ 1 for $\mathrm{F}$ and $2.4 \cdot 10^{-8} \mathrm{~mol} / 1$ for HMF in the aqueous honey solution. These values correspond to $5 \cdot 10^{-3}$ and $8 \cdot 10^{-3} \mathrm{mg} / \mathrm{kg}$ of honey respectively, well below the detection limits reported by other authors for the determination of HMF by HPLC without derivatization $[6,10,12]$.

\subsection{Specificity, recovery and reproducibility}

The method shows a high specificity because, under the described conditions, the derivatives of both $\mathrm{F}$ and HMF are well separated from the other carbonyl compounds present in the sample under examination. As an example, Fig. 4 shows a typical separation obtained on a commercial sample of honey. The identity of the peaks was established by co-injection with the corresponding pure standards.

To verify the absence of interferences with the two analytes of interest, the fractions obtained from the chromatographic run were subjected to mass spectrometric analysis. The mass spectrum of the compound corresponding to the DNPH-one of F showed the molecular ion $\mathrm{M}^{+}$at $\mathrm{m} / \mathrm{z} 276$; moreover, the mass spectrum was in excellent agreement with that of the DNPH-one of a F standard. The mass spectrum of the HPLC fraction corresponding to the derivative of HMF showed the molecular ion $\mathrm{M}^{+}$at $\mathrm{m} / \mathrm{z}$ 306; again, the mass spectrum was in excellent agreement with that of the DNPH-one of a HMF standard.

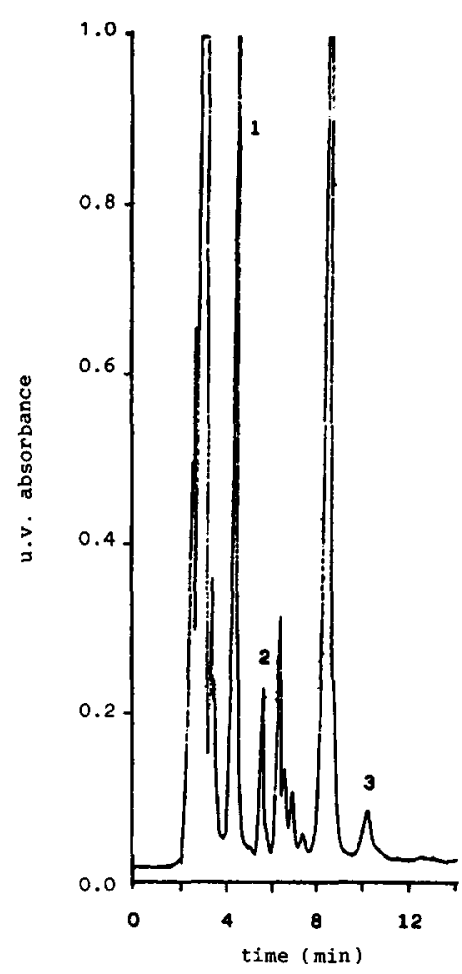

Fig. 4. High-performance liquid chromatographic separation of the 2,4-dinitrophenylhydrazones of carbonyl compounds from a commercial sample of honey. For conditions of analysis see Section 2. Peak identification: 1, 2,4-dinitrophenylhydrazine; 2, 2,4-dinitrophenylhydrazone of 5-hydroxymethyl-2-furaldehyde; 3, 2,4-dinitrophenylhydrazone of 2-furaldehyde.

Honey shows a highly variable composition of minor components, both in concentration and nature, several of which are carbohydrates that may form the corresponding DNPH-ones during the preliminary derivatization step. However, in none of the samples so far examined by us have we observed interferences with the two analytes of interest. On the contrary, interferences may occur when the aqueous honey solution is directly injected into the HPLC system [10].

DNPH must be at least twenty times more concentrated than the analytes to be determined in the analyses of real samples, as an aliquot of the reagent is employed in the derivatization of the other carbonyl compounds present. In all the samples so far examined, a 1:20 ratio was sufficient, as (i) a large peak of the DNPH excess appears in the chromato- 
gram and (ii) area increments were not obtained for the two analytes of interest by utilizing a 1:50 analyte-to-reagent ratio.

Recoveries were determined by adding known amounts of both analytes to an aqueous honey solution. The amount found in respect of the sum between the amount added and that originally present in the sample represents the recovery. The honey was selected on the basis of its low content of both $\mathrm{F}$ and HMF $\left(3.6 \cdot 10^{-6}\right.$ and $3.3 \cdot 10^{-5} \mathrm{~mol} / \mathrm{l}$, respective$\mathrm{ly}$, in the aqueous sample solution, corresponding to 0.9 and $10.4 \mathrm{mg} / \mathrm{kg}$ of honey), two of the lowest levels among those which we found in real samples. The results obtained are shown in Table 1. Recoveries for both analytes ranged from 95 to $99 \%$, that is, no significant loss was observed during the clarification step by employing the Carrez solution. Virtually quantitative recoveries of HMF from honey have been already reported by several authors employing various methods of preliminary sample preparation $[4,6-10,12,20]$.

Reproducibility was evaluated by carrying out the determination on six different aliquots of the same sample over a period of $48 \mathrm{~h}$; each solution was injected twice. The average concentration of $F$ was $3.6 \cdot 10^{-6} \mathrm{~mol} / \mathrm{l}$, with a standard deviation of 1.1 .

Table 1

Recoveries of 2-furaldehyde and 5-hydroxymethyl-2-furaldehyde added to honey ${ }^{\mathrm{a}}$

\begin{tabular}{|c|c|c|}
\hline \multicolumn{2}{|c|}{ Concentration $(\mathrm{mol} / \mathrm{l})$} & \multirow[t]{2}{*}{ Recovery $(\%)$} \\
\hline Added & Found & \\
\hline \multicolumn{3}{|c|}{ 2-Furaldehyde } \\
\hline $1.0 \cdot 10^{-7}$ & $(3.66 \pm 0.03) \cdot 10^{-6}$ & $99 \pm 1$ \\
\hline $1.0 \cdot 10^{-6}$ & $(4.51 \pm 0.08) \cdot 10^{-6}$ & $98 \pm 2$ \\
\hline $1.0 \cdot 10^{-5}$ & $(1.32 \pm 0.03) \cdot 10^{-5}$ & $97 \pm 2$ \\
\hline $1.0 \cdot 10^{-4}$ & $(9.84 \pm 0.20) \cdot 10^{-5}$ & $95 \pm 2$ \\
\hline $1.0 \cdot 10^{3}$ & $(9.73 \pm 0.30) \cdot 10^{-4}$ & $97 \pm 3$ \\
\hline \multicolumn{3}{|c|}{ 5-Hydroxymethyl-2-furaldehyde } \\
\hline $1.0 \cdot 10^{\circ}$ & $(3.30 \pm 0.09) \cdot 10^{-5}$ & $97 \pm 3$ \\
\hline $1.0 \cdot 10^{5}$ & $(4.25 \pm 0.04) \cdot 10^{-5}$ & $99 \pm 1$ \\
\hline $1.0 \cdot 10^{\circ}$ & $(1.27 \pm 0.03) \cdot 10^{-4}$ & $95 \pm 2$ \\
\hline $1.0 \cdot 10^{-3}$ & $(9.92 \pm 0.30) \cdot 10^{-4}$ & $96 \pm 3$ \\
\hline
\end{tabular}

"Mean of six determinations \pm S.D..

The amounts of furaldehyde and hydroxymethylfuraldehyde originally present in the sample were $3.6 \cdot 10^{-6}$ and $3.3 \cdot 10^{-5} \mathrm{~mol} / \mathrm{l}$ respectively. The sample was spiked by the amounts specified in the table.
$10^{-7} \mathrm{~mol} / 1$ and a relative standard deviation of $3 \%$; the average concentration of HMF was $3.3 \cdot 10^{-5}$ $\mathrm{mol} / \mathrm{l}$, with a standard deviation of $6.6 \cdot 10^{-7} \mathrm{~mol} / \mathrm{l}$ and a relative standard deviation of $2 \%$.

The derivatization step was carried out on the same sample of honey for $30,60,90$ and $120 \mathrm{~min}$ to verify that artifactual amounts of either of the analytes of interest are not produced during the preliminary sample processing under acidic conditions; each solution was injected three times. A slight increase of the amount of $F$ was obtained at $60 \mathrm{~min}$, followed by a decrease at $90 \mathrm{~min}$ down to a level even lower than at $30 \mathrm{~min}$ and a subsequent increase at $120 \mathrm{~min}$. As far as the HMF content is concerned, a slight increase was observed at $60 \mathrm{~min}$, followed by a decrease at $90 \mathrm{~min}$ and a subsequent increase at $120 \mathrm{~min}$. However, none of the values obtained for both $\mathrm{F}$ and HMF was significantly different $(p<$ 0.05 ) in respect of the amount observed at $30 \mathrm{~min}$.

\subsection{Application}

The procedure was applied to the determination of $\mathrm{F}$ and HMF in several samples of commercial honeys purchased from local shops; each sample was analyzed in duplicate. The amounts of $F$ ranged from 0.52 to $1.74 \mathrm{mg} / \mathrm{kg}$ and the amounts of HMF from 10.42 to $56.75 \mathrm{mg} / \mathrm{kg}$ of honey. Moreover, in all the samples analyzed the amount of HMF was one order of magnitude greater than the amount of $F$.

\section{Conclusions}

The HPLC method described allows the quantitative determination of $\mathrm{F}$ and HMF in honey over a wide range of concentrations. The specificity obtained by preparing the DNPH-ones of the carbonyl compounds present in the sample is better than that obtained by injecting an aqueous honey solution without derivatization. Both $F$ and HMF were determined in all the samples analyzed by us, whereas $F$ was often not detected in previous HPLC reports $[9,21]$. The preparation of the DNPH-ones in a water-acetonitrile solution allows the direct injection into the HPLC system. 


\section{References}

[1] J.E. Schade, G.L. Marsh and J.E. Eckert, Food Res., 23 (1958) 446.

[2] J.W. White Jr., I. Kushnir and M.H. Subers, Food Technol., 18 (1964) 153.

[3] J.W. White Jr. and J. Siciliano, J. Assoc. Off. Anal. Chem., 63 (1980) 7.

[4] S. Marini and G. Righi, Ind. Aliment., 24 (1985) 693.

[5] F. Salinas, A. Espinosa Mansilla and J.J. Berzas Nevado, Fresenius' J. Anal. Chem., 340 (1991) 250.

[6] P. Vinas, N. Campillo and M. Hernandez Cordoba, Food Chem., 44 (1992) 67.

[7] A.K. Dhar and B.R. Roy, Analyst, 97 (1972) 981.

[8] J.W. White Jr., J. Assoc. Off. Anal. Chem., 62 (1979) 509.

[9] H.J. Jeuring and F.J.E.M. Kuppers, J. Assoc. Off. Anal. Chem., 63 (1980) 1215.

[10] J. Serra Bonvehi, Sci. Aliments, 11 (1991) 547.

[11] R.M. Mijares, G.L. Park, D.B. Nelson and R.C. McIver, J. Food Sci., 51 (1986) 843.

[12] H.-J. Kim and M. Richardson, J. Chromatogr., 593 (1992) 153.

[13] D. Tu, S. Xue, C. Meng, A. Espinosa-Mansilla, A. Munoz de la Pena and F. Salinas Lopez, J. Agric. Food Chem., 40 (1992) 1022.

[14] D.W. Lord, M.J. Scotter, A.D. Whittaker and R. Wood, J. Assoc. Public Anal., 26 (1988) 51.

[15] H.L. Dinsmore and S. Nagy, J. Assoc. Off. Anal. Chem., 57 (1974) 332.
[16] J.E. Marcy and R.L. Rouseff, J. Agric. Food Chem., 32 (1984) 979.

[17] J. Fiehe, Z. Unters. Nahr. Genuss., 16 (1908) 75.

[18] E. Feder, Z. Unters. Nahr. Genuss., 22 (1911) 412.

[19] G.R. Lappin and L.C. Clark, Anal. Chem., 23 (1951) 541.

[20] O. Winkler, Z. Lebensm.-Unters. -Forsch., 102 (1955) 161.

[21] M. Wootton and L. Ryall, J. Apic. Res., 24 (1985) 120.

[22] M.A. Carey and H.E. Persinger, J. Chromatogr. Sci., 10 (1972) 537.

[23] F. Lipari and S.J. Swarin, J. Chromatogr., 247 (1982) 297.

[24] J.G. Kirchner and G.J. Keller, J. Am. Chem. Soc., 72 (1950) 1867.

[25] R.G. Rice, G.J. Keller and J.G. Kirchner, Anal. Chem., 23 (1951) 194

[26] H. van Duin, Nature, 180 (1957) 1473.

[27] J.G. Kirchner, J.M. Miller and G.J. Keller, Anal. Chem., 23 (1951) 420.

[28] J. Cason and E.R. Harris, J. Org. Chem., 24 (1959) 676.

[29] R.L. Stephens and A.P. Teszler, Anal. Chem., 32 (1960) 1047.

[30] J.W. Ralls, Anal. Chem., 32 (1960) 332.

[31] L.J. Papa and L.P. Turner, J. Chromatogr. Sci., 10 (1972) 747.

[32] R.J. Kleber and K. Mopper, Environ. Sci. Technol., 24 (1990) 1477.

[33] D.L. Massart, A. Dijkstra and L. Kaufman, Evaluation and Optimization of Laboratory Methods and Analytical Procedures, Elsevier, Amsterdam, 1978. 